\title{
Appropriate harvest maturity for mango (Mangifera indica L.) fruit using age control and fruit growth and development attributes
}

\begin{abstract}
Haden, Kent, Palmer, and Keitt mango varieties were studied to determine the time and harvest maturity indices appropriate for the export and local markets. Randomized complete block design was used with four replications. Five trees each of the four varieties were sampled at random in each of the four replications. Date of fruit-set was noted and sampled trees tagged accordingly.Haden, Kent, Palmer, and Keitt mango varieties were harvested at $112,126,133$, and 140 days and at 126, 140,147, and 154 days after fruit-set, for sea and air freights respectively; at 126, 140,147, and 154 days and at 119, 133, 140, and 147 days after fruit-set, for local markets closer and farther away respectively. Fruit pulp colour, fruit indentation, pedicel colour, fruit peel, grooves at the stylar scar end of fruit, and starch concentration were determined in conjunction with fruit age at physiological maturity.
\end{abstract}

Keywords: mango, fruit, harvest, maturity, age control, growth, development, attributes, visual means, physiological, climacteric

\author{
Volume 4 Issue 5 - 2020 \\ Moomin Abu,' Nana S Olympio, ${ }^{2}$ Joseph Ofei \\ Darko 3 \\ 'Department of Horticulture, Faculty of Agriculture, University \\ for Development Studies, Ghana \\ ${ }^{2}$ Department of Horticulture, Kwame Nkrumah University of \\ Science and Technology, Ghana \\ ${ }^{3}$ Department of Agricultural Engineering, Kwame Nkrumah \\ University of Science and Technology, Ghana
} Faculty of Agriculture, University for Development Studies, Nyankpala, Northern Region, Ghana, Tel 0244849469, Email moonbu@yahoo.com

Received: October 01, 2020 | Published: October 16, 2020

\section{Introduction}

Exports of fruits and vegetables are one of the most vibrant sectors of the Ghanaian economy. Over the years the sector has grown by leaps and bounds with successes not for the presence of the few large foreign-owned corporations, but because the export industry also relied on the existing few larger/big-time producers and an enormous number of small-holder mango out-growers. Despite these successes the country has embarked on a policy of crop diversification, making mango Ghana's next big entry to the EU and other markets. ${ }^{1,2}$ Mango is cultivated in many tropical and subtropical regions and distributed widely in the world. It is one of the most extensively exploited fruits for food, juice, flavour, fragrance, and colour. In several cultures, its fruit and leaves are ritually used as floral decorations at weddings, public celebrations, and religious ceremonies. ${ }^{3}$

According to Abu et al and Okorley et al. ${ }^{4}$ most mango farmers in Ghana have difficulty in determining the appropriate stage of mango fruit harvest maturity that would be suitable for the export and local markets. But Litz. ${ }^{5}$ reiterated that the key issues or attributes of preharvest management that affect or influence postharvest development of mangoes include fruit maturity, colour (internal and external), shape, size, sweetness, position-on-tree, vitality, incidence of pests and diseases or biotic/abiotic damage, weather conditions before or at harvest, frequency of irrigation, and nutrient content. In any given tree/orchard/district/season, such attributes vary. ${ }^{5}$

Okorley et al. ${ }^{4}$ reported that Haden, Kent, Palmer, and Keittmango varieties are the main export varieties, the most preferred in both export and local markets, and are also those that are highly cultivated among the exotic varieties known in Ghana. Although the mango industry in Ghana has been almost entirely dominated by a comparatively large number of the local cultivars, Haden, Kent, Palmer, and Keittvarieties have reportedly been cropped on a comparatively higher acreage with high productivity. ${ }^{4}$ According to the authors, mango farmers in Ghana consist of both commercial and small-scale producers but with a preponderance of the latter. The small-scale producers, the majority of whom are illiterate, depend on visual attributes for determining harvest maturity most probably because they are often unable to set definite standards. ${ }^{6,7}$ Mixed re-actions on the criteria to adopt to determine appropriate mango fruit harvest maturity suitable for the export and local markets remain among growers/producers. Some growers have been successful whereas others have always ponded on what criteria to adopt to meet the export as well as the local market harvest maturity requirements.

According to Kitinoja and Kader, ${ }^{8}$ the basic requirement for prediction of maturity is to have a measurement that can be made prior to, but which is highly correlated with the date of maturation. The authors added that the simplest prediction system uses measurements which relate to development of the fruit in a regular way through to the latter part; and that appropriate maturity indicators provide indices which can be related to storage life, ripening attributes, and marketability. According to Litz, ${ }^{5}$ lack of simple and reliable methods for determining the stage of fruit maturity also affect quality. For Iqbal, ${ }^{8}$ one of the major problems currently restricting international trade in mangoes is the variation in physiological maturity in a single consignment. The International Plant Genetic Resources Institute's provisions include among other quite important plant data; maturity period, productivity, eating quality, and attractiveness. ${ }^{10}$

Singh et al. ${ }^{11}$ indicated that fully mature mango fruit are strictly those which have produced a fully developed seed and which have reached their full physiological potential for size increase and dry matter accumulation within the constraints of the growth environment. The authors reiterated that when fruits are detached from the tree 
before the onset of ripening, they are initially hard and green. The fruit progressively softens, change colour and develop aroma at a rate determined by storage environment and at-harvest maturity. According to the authors there is a range of maturity levels within which detached fruit will develop acceptable ripe fruit attributes. The authors added that measurements of variables such as dry matter or flesh colour provide indices which can be related to accumulated information on storage life, ripening attributes, and marketability of fruit.

The rate at which ripening occurs under particular storage conditions will depend upon the stage of ontogeny at harvest. More mature fruit will ripen more rapidly than less mature fruit. ${ }^{5}$ Teutsch ${ }^{12}$ stated that maturity assessment may be on the basis of dry matter, flesh colour, skin colour, fruit shape, brix, specific gravity or days from flowering. According to the author, flesh colour is favoured in South Africa while in Australia, skin colour and dry matter determination may be considered as well; information would however be cultivarspecific. ${ }^{12}$ Marques et al. ${ }^{13}$ reiterated that easy-to-assess harvest indices determined by using visual attributes are needed and they must correlate with the recognized variables measured in prescribed tests. The authors added that workers who harvest and grade fruit should be trained and tested for their ability to accurately select fruit according to the preferred non-destructive index. Marques et al. ${ }^{13}$ however testified that visual assessment of maturity is complicated by the fact that cultivars differ and fruits on the same tree may vary significantly in maturity levels due to prolonged or uneven flowering.

If fruits in a single consignment are of mixed maturity levels, it is impossible to find an effective storage regime which will ensure good quality on arrival. One fruit of more advanced maturity among other fruits in a container can accelerate the ripening of all fruit, resulting in fruit health disorders and subsequent short storage life and poor produce quality. Joyce et al. ${ }^{14}$ and Kouno et al. ${ }^{15}$ also earlier on stated that future research should consider easy-to-apply harvest indices and non-destructive methods for checking fruit maturity which could be incorporated in an automated grading system.

Ledesma et al. ${ }^{16}$ attested that on-farm record keeping of seasonal produce maturity, orchard management schedules, environmental data, transport regimes, market destinations, and out-turn problems may enable some prediction of future produce performance. The authors added that improvements in produce quality and performance resulting from the effective use of such records can provide considerable competitive advantages when developing product brand loyalty.

The objective of the study was to determine and establish the optimum age and accompanying visual attributes/characteristics of mango fruit harvest maturity as indices for the appropriate time to harvest for export and local markets.

\section{Materials and methods}

\section{Experimental site, period and plant materials}

Field studies were conducted to determine appropriate mango fruit harvest maturity, through age control, regular visual observations/ inspection, and subsequent photographing of changes in fruit development attributes at different stages, intended for the export and local markets. Four major export mango varieties (Haden, Kent, Palmer, and Keitt) which are appreciated by importers of mango exported from Ghana, ${ }^{4,17.18}$ were used for the study. The study was conducted at Prudent Export and Import Company Ltd Mango Plantation in the Somanya-Dodowa mango production zone of the Dangme West District in the Greater Accra Region of Ghana. Two major (April to July) and two minor (December to February) seasons were used for the experiment.Randomized Complete Block Design (RCBD) was used with four replications.

\section{Sampling and determination of optimum harvest maturitytime for mango fruit through age control and fruit development attributes}

Five mango trees in each caes of the four varieties were sampled at random in each of the four replications. Date of fruit-set initiation was noted on each sample tree. On each sample tree, ten different panicles (all initiating fruit-set) were sampled and tagged. One fruit was then sampled from each of these ten different panicles for the study. The number of days each of the ten fruits sampled per tree took from fruit-set to harvest maturity was recorded, summed up, and averaged in each case of the five trees sampled per replication, for the four varieties. The figure obtained represented the number of days from fruit-set to harvest maturity (early, mid or late harvest) foreach sample fruit on the sample tree; denoting age of fruit from fruit-set. ${ }^{9,19,20}$ The experiment was replicated four times and values presented as means.

All visual determinations made on fruit growth and development attributes/characteristicswere in relation to the age control criterion. Parameters considered for visual studies on fruit growth and development attributes were changes in fruit pulp/flesh colour, depth of fruit indentation at its proximal end, purplish-red blush colour of pedicel (first segment from the proximal end of the fruit), leathery fruit peel/skin; ${ }^{21}$ and level of starch concentration in the fruit. ${ }^{22}$ These attributes were determined fortnightly by regular visual observation/ inspection and photographing. ${ }^{12,20}$ For convenience with respect to optimum data management, the last four fortnightly data obtained and recorded in each case of the different visual parameters studied were used as terminal results. All determinations were made in relation to the age control criteria followed in the experiment. Termination of data collection for both age control and in each case of the different visual parameters in this regard was, however, at physiological maturity or pre-climacteric stage (green-hard, out grown shoulders, pita round the stalk-end, turning yellow or showing an apparent break of yellow colour in the pulp/flesh). According to Abu and Iqbal, ${ }^{9,20}$ the number of days from fruit-set to harvest provides one of the Best and reliable indicators of maturity early, midorlate harvest) and represents the optimum age of the fruit for quality post-harvest behaviour. Dadzie and Orchard, ${ }^{22}$ and Manasa et al. ${ }^{23}$ indicated that High starch content is represented by a higher degree of dark-blue colouration of fruit pulp/flesh and that the starch index pattern is used to distinguish among the various stages of growth and development of fruit.

\section{Statistical analysis}

All data were analysed using the Analysis of Variance (ANOVA) technique ${ }^{24}$ with the GENSTAT statistical program. Least Significant Difference (LSD) at $5 \%$ probability was used to determine treatment differences among varieties. Separate analyses were carried out with the data for each of the seasonal trials. The errors for these ANOVAS were tested for homogeneity of variance ${ }^{24}$ and found to be statistically not different at $p>0.05$, so the results for the seasonal experiments were pooled for analysis. 


\section{Results}

Age control method for determining appropriate harvest maturity time for mango fruit at the preclimacteric stage

For Haden, Kent, Palmer and Keitt mango varieties, the average physiological maturity ages of fruits at early harvest were determined and established to be 112,126, 133, and 140 days after fruit-set, respectively (Table 1). The ages for mid harvest were determined and established to be 119, 133, 140, and 147 days after fruit-set for Haden, Kent, Palmer, and Keitt fruits, respectively. For late harvest, the ages were determined and established to be 126, 140, 147, and 154 days after fruit-set for Haden, Kent, Palmer, and Keitt fruits, respectively (Table 1). Haden fruits matured earlier than fruits of the other varieties while Keitt fruits matured later.

Table I Harvest periods/time-ranges for Haden, Kent, Palmer, and Keitt mango varieties at physiological maturity

\begin{tabular}{llll}
\hline Variety & Early harvest (days from fruit-set) & Mid-harvest (days from fruit-set) & Late harvest (days from fruit-set) \\
\hline Haden & $109-115$ & $116-122$ & $123-129$ \\
Kent & $123-129$ & $130-136$ & $137-143$ \\
Palmer & $130-136$ & $137-143$ & $144-150$ \\
Keitt & $137-143$ & $144-150$ & $151-157$ \\
\hline
\end{tabular}

Generally, the average physiological maturity ages for early, mid, and late harvests were seven days apart in each case of the four varieties.
Table 2 shows atypical picking and shipping schedule for mango fruits consigned by sea and by air to the European Union from Ghana. The sea freight takes much longer time (20-27 days), almost three to four times that of air freight (about 6 days).

Table 2 Typical picking and shipping schedule for mango fruits consigned by sea and by air to the European Union from Ghana

\begin{tabular}{lll}
\hline \multirow{2}{*}{ Operation } & \multicolumn{2}{l}{ Days required } \\
\cline { 2 - 3 } & sea freight & Air freight \\
\hline Picking and Packaging & $\mathrm{I}$ & $\mathrm{I}$ \\
Pre-cooling and accumulation of load & $\mathrm{I}$ & $\mathrm{I}$ \\
Transport to port, port handling, and accumulation of load & $\mathrm{I}$ & $\mathrm{I}$ \\
Voyage time & $\mid \mathrm{I}-2 \mathrm{I}$ & 0.25 \\
Discharge handling & $\mathrm{I}$ & $\mathrm{I}$ \\
Transport and distribution & 2 & $\mathrm{I}$ \\
Total & $20-27$ & 5.25 \\
\hline
\end{tabular}

\section{Visualattributes/characteristicsfor determining appropriate harvest maturity time for mango fruit at the pre-climacteric stage}

Visual physiological maturity indices were determined on mango fruit pulp/flesh colour; mango fruit shape/fullness of mango fruit cheeks/outgrown shoulders/fruit indentation; mango fruit starch content; leathery fruit peel/skin; presence of ridges or grooves at the stylar scarend of the fruit or the proximal end of the fruit, specifically for Palmer; and changes in colour of fruit pedicel (first segment from the proximal end of the fruit) (Figures 1-5). Specific descriptions are outlined for each associate Figure.

Haden, Kent, Palmer, and Keitt mango fruits showed distinct paleyellow colouration on the flesh/pulp around the stone/seed at their physiological maturity stages for early harvest (harvest at 112, 126, 133 and 140 days after fruit-set, respectively) (Figure 1).

At physiological maturity, Haden, Kent, and Keitt mango fruits' indentation depths or cheeks of the fruits were fully developed (pit created around the point of attachment of the pedicel to the fruit) and the pedicels (segment/segments of the pedicel closer to the proximal end of the fruit) developed a purplish-red blush colour (Figure 2). The Palmer variety is an exception in this context; rather its fruit's physiological stage harvest maturity is determined by the intensity of depressions/ridges/grooves around the stylar scarend of the fruit (Figure 3).

The concentration of starch in fruit pulp/flesh continued to increase during growth and subsequent development toward fruit maturity in all the varieties when the starch iodine test was conducted (Figure 4). Starch concentration increased gradually up to physiological maturity where the pulp/flesh colour depicteda higher degree of darkblue colouration (Figure 4). When the fruits were yet in their growth and development stage before physiological maturity, iodine reaction occurred very gradually and the pulp/flesh colour stained a pale tan colour as indicated in the early stages (Figure 4).

Figure 5 shows a leathery fruit peel/skin with white-powdery gloss as another maturity attribute that matches the fruit age and the other fruit development attributes at the pre-climacteric stage. This attribute also occurs in all varieties. 

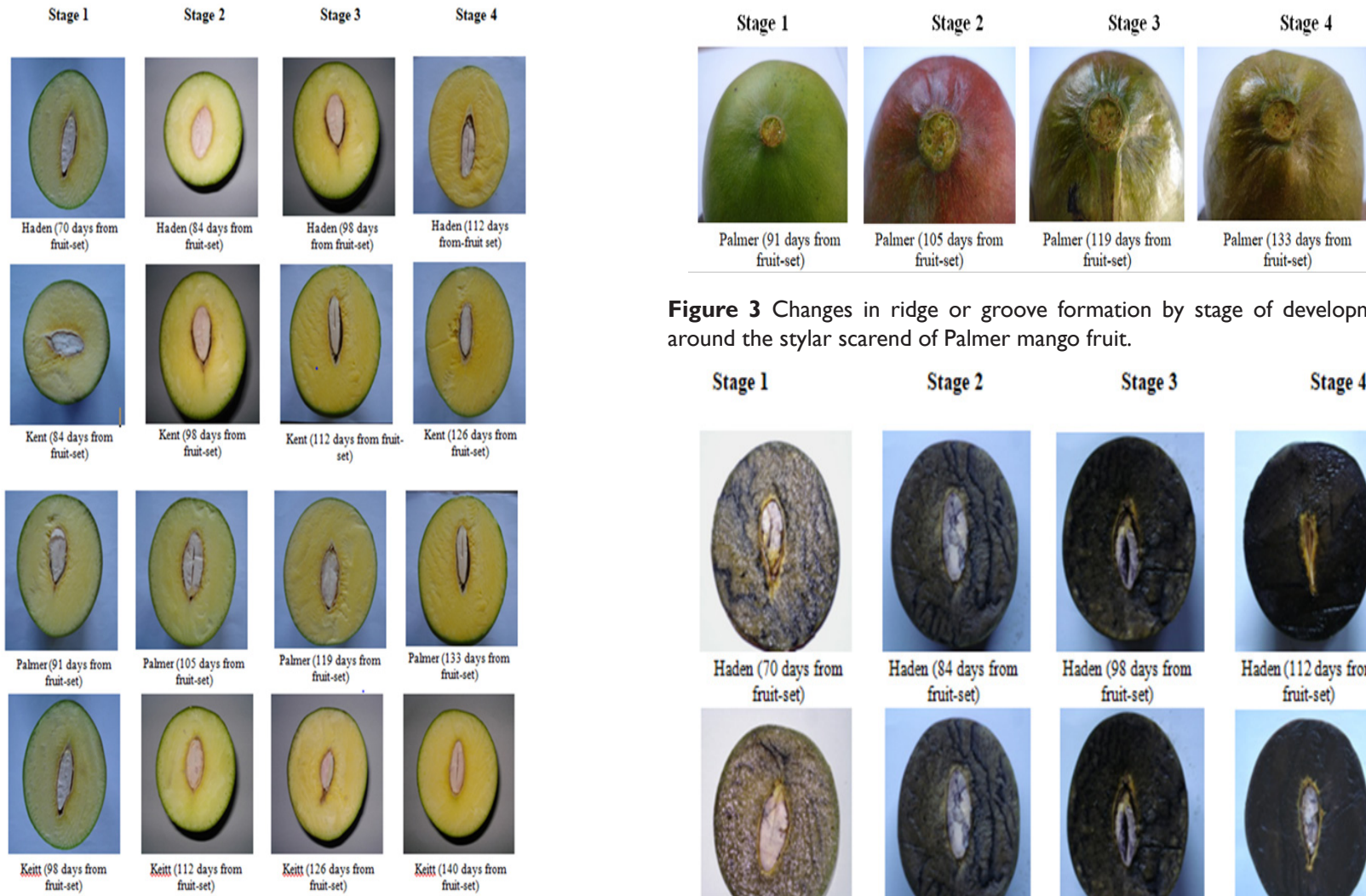

Figure 3 Changes in ridge or groove formation by stage of development around the stylar scarend of Palmer mango fruit.

Stage 1

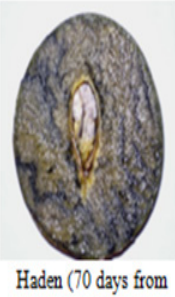

fruit-set)

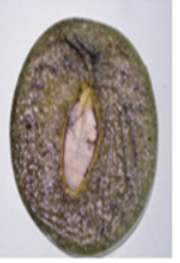

Kent ( 84 days from

fruit-set)

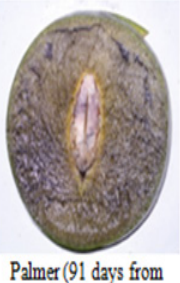

fruit-set)

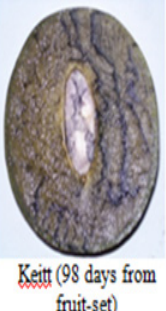

Stage 2

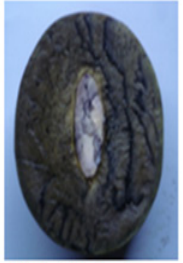

Haden (\$4 days from

fruit-set)

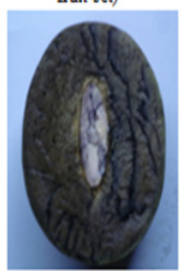

Kent ( 98 days from

fruit-set)

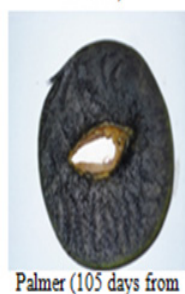
fruit-set)

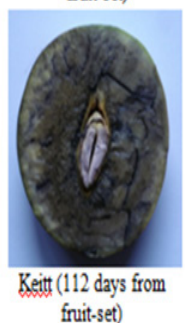

Stage 3

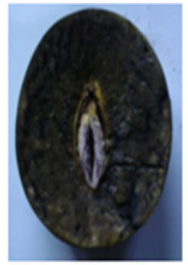

Haden (98 days from fruit-set)

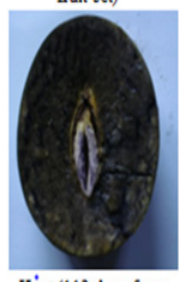

Kent (112 days from fruit-set)
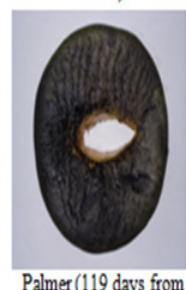
fruit-set)

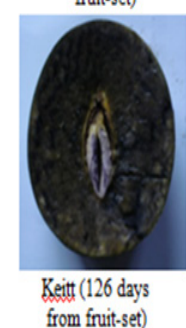

Stage 4

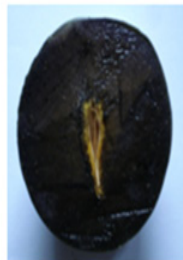

Haden (112 days from fruit-set)

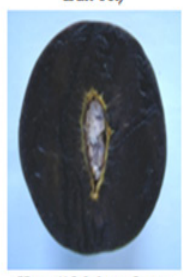

Kent (126 days from

fruit-set)

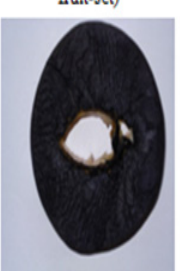

Palmer (133 days from fruit-set)

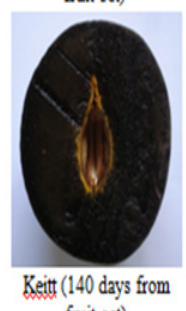

Figure 4 Changes in mango fruit pulp/flesh starch content by stage of development for Haden, Kent, Palmer, and Keitt varieties. The degree of darkblue colouration intensifies as development advances.
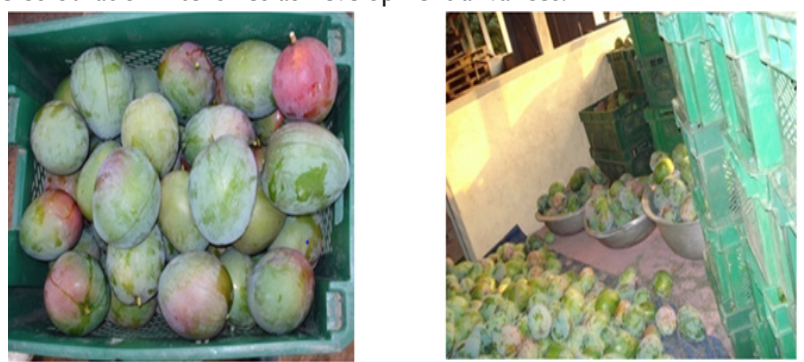

Figure $\mathbf{5}$ Leathery fruit peel/skin with white-powdery gloss at physiological

Figure 2 Mango fruit indentation depth and pedicel (segment/segments of the pedicel closer to the proximal end of the fruit) colour changes by stage of development for Haden, Kent, Palmer, and Keitt varieties. maturity. 


\section{Discussion}

The physiological maturity ages for Haden, Kent, Palmer, and Keitt mango fruits obtained from the number of days from fruit-set to harvest, showed that Keitt and Palmer are late maturing varieties; Kent, a medium maturing variety; and Haden, an early maturing variety. All physiologically mature fruits subjected to study showed peculiar accompanying visual fruit development attributes/characteristics along-side maturity ages for the different levels as either early, mid, or late harvest maturity, as indicated in the results column of this paper.

Ghana's mangoes (fresh and processed forms) are largely exported by both air and sea freights where air freights take at most 6 hours and sea freights, a range of 14-21 days to various destinations with particular reference to the European Union countries who are major importers of mangoes produced in Ghana. ${ }^{18,20,25,26}$ Hence, the need to consider both air and sea freights, and even local market demand where the determination of the appropriate harvest maturity for mango fruit with particular reference to time (time with accompanying maturity attributes/characteristics) is the main concern. To simulate sea freight and other intended far-reaching market destinations where fruit for the fresh market was transported to, fruits of Haden, Kent, Palmer, and Keitt mango varieties were harvested at 112, 126, 133, and 140 days after fruit-set, respectively, for early maturity (pre-climacteric). Asgharzade et al. ${ }^{27}$ observed that by analogy with apples, the stage of maturity being just before the climacteric rise in respiration, would appear to be a suitable stage of maturity for maximum transport and storage. For fresh market fruit to be transported by air freight, fruit for processing, and fresh market fruit for the local market, fruits of Haden, Kent, Palmer, and Keitt mango varieties were harvested at $126,140,147$, and 154 days after fruit-set, respectively, for late maturity. $\mathrm{Abu}^{19}$ and Ambuko et al..$^{28}$ observed that fruit, especially for export, should be harvested earlier and that the time for harvesting should be established on the basis of the type of market, distance from the orchard or the packing house, and the type of transport to be used. According to the authors, fruit has to be harvested at the ideal stage in order to allow for the development of the most adequate organo leptic quality and the longest post-harvest life.

Mid or late harvest stage can be applied for fruit intended for local market, processing or intended to be consumed very close to the orchard. Fruit to be sold in distant markets within the country which needs to be kept for a few days to a week before being sold/consumed should be harvested at early harvest but at the higher side of the timerange $(115,129,136$, and 143days from fruit-set, for Haden, Kent, Palmer, and Keittmango varieties, respectively). Where customers/ consumers are accustomed to ripe fruits, and where the distance is short, fruit can be harvested between full maturity and early stages of ripening (mid or late harvest). Thus, fruit should always be harvested at full maturity and before full ripe, but should never be harvested over-ripe or immature for any market. ${ }^{20,29,30}$

With most mango cultivars/varieties, including Haden, Kent, Palmer, and Keitt, fruit flesh/pulp colour changes are consistent as fruit advances in growth and development. Unfortunately, this is a destructive index, but its application for determining the appropriate stage of mango fruit harvest maturity has been found to be more reliable and consistent than the application of skin colour change in the same context. ${ }^{22}$ The author added that mango fruit flesh/pulp colour changes from whitish to bright-yellow as it advances in growth and development; and for Okoth et al. ${ }^{31}$ flesh/pulp colour is commonly used as a maturity index in several mango growing regions.

According to Hemat et al. ${ }^{32}$ mango flesh/pulpcolor attributes ( $a, b, L, \Delta E$, chroma, and Hue angle) are also an important quality index. They added that the strongest color intensity was recorded for flesh/pulp of Sinara, Sedeka, Awis, and Zibdia mango cultivars common in Egypt. Hemat et al. ${ }^{32}$ reported that at physiological maturity, reddish/yellow color shade was shown in the flesh/pulp of Awis, Sinara, Alfonse, and Zibdiamango cultivars while the flesh/pulp of Sukari and Sedeka mango cultivars showed a greenish yellow color shade. Other findings by Hemat et al. ${ }^{32}$ indicated that at physiological maturity Alfonse, Awis, Sinara, and Zibdia mango fruit flesh/pulp showed orange-yellow coloration, while a pure yellow and yellowgreen coloration was shown in the flesh/pulp of Sedeka and Zibdia mango cultivars, respectively. Findings by Spinelli et al. ${ }^{33}$, VásquezCaicedo et al. ${ }^{34}$ and Singh et al. ${ }^{35}$ showed similar results, while Okoth et al..$^{31}$ attested that flesh/pulp colouration of different mango varieties studied was found to be similar at physiological maturity.

Significant increases in dry matter and starch content in all the varieties was observed as fruit growth, development, and subsequent maturation advanced. This is depicted by a stained pale- tan colouration through gradual dark-blue colouration to a higher level of dark-blue colouration of the fruit flesh/pulp colour at physiological maturity. However, this posts a limitation since differences in fruit flesh/pulp colour among the different stages of high starch content at preclimacteric/physiological maturity/mature green stage, in each case of the different varieties were not significantly distinct. Muengkaew et al. ${ }^{36}$ confirmed this finding. This finding is also confirmed by Dadzie and Orchard ${ }^{22}$ in their studies on bananas. According to Desphande et al. ${ }^{37}$ the stage of maximum starch content of fruit was a good index of full maturity for harvesting Alphonso, Pairi, and Kent mango varieties. This was also confirmed for some Indian mango varieties. ${ }^{9}$

For Haden, Kent, and Keitt mango varieties, the cheeks of the fruits were fully developed (out-grown shoulders or fruit indentation at its proximal end) with pit around the point of attachment of the pedicel to the fruit, and the pedicels (segment/segments of the pedicel closer to the proximal end of the fruit) developed purple-red blush colours at physiological maturity $(112,126$, and 140 days from fruitset). These also matched with fruit flesh/pulp colour changes from whitish to pale-yellow and the appearance of a leathery fruit peel/skin with white-powdery glosson the surface of the mango fruits at the preclimacteric stage, ${ }^{38}$ which are all indicators of physiological maturity in all the varieties studied. ${ }^{39}$ Similar observations were reported by Gill et al ${ }^{40}$ and Ellong et al. ${ }^{41}$ Hofman and Ledger ${ }^{42}$ earlier on reported that in South Africa, flesh colour is favoured for assessing mango fruit maturity, while in Australia, skin colour, dry matter, and accumulated heat units are considered as well. Palmer is an exception in this context of applying/using the depth of fruit indentation at its proximal end as a maturity index, rather its harvest maturity is determined by the intensity of depressions with ridges/grooves around the stylarscar-end of the fruit. The intensity of depressions with ridges/grooves around the stylar-scar-end of the fruit occurred in conjunction with the formation of the other visual attributes/characteristics of the mango fruit harvest maturity indices discovered earlier in this study. $\mathrm{Abu}^{20}$ reported that Haden, Kent, and Keitt mango fruits were harvested at physiological maturity when fruits of each of the different varieties maintained a constant indentation depth of $0.25,0.49$, and $0.50 \mathrm{~cm}$, respectively. According to the author, Palmer fruits did not show any indentation of the sort from growth through development to physiological maturity, but the harvest maturity index attribute/ characteristic determined and established was the intensity of ridges/ grooves around the stylar scar end of its fruit.

Iqbal $^{9}$ reported that fully mature mango fruits show significant depths of indentation (out-grown shoulders) in some cultivars and depressions with ridges/grooves in some other cultivars but they all 
occur at the proximal endof the fruit (the point of attachment of the pedicel to the fruit), and that they are firm and green in some cultivars. According to the author these criteria are used in several mango producing regions but are cultivar dependent and must be considered with other factors. By analogy with apples, this stage, being just before the climacteric rise in respiration, would appear to be a suitable stage of maturity for enhanced transport and storage. ${ }^{43}$

Ages of fruits were determined objectively though laborious and time-consuming because of the need to obtain baseline data and fruit growth and development attributes were determined subjectively in conjunction with fruit age, but required no sophisticated equipment and was easy to operate. But standards must be quantitative and not qualitative. The approach then was to combine several methods of assessing maturity stage in order to establish appropriate harvest maturity time and indices that would enhance mango export and improve the local market.

\section{Conclusion}

Fruit age, fruit flesh/pulp colour, depth of fruit indentation at its proximal end, level of starch concentration in the fruit, colour ofpedicel (first segment from the proximal end of the fruit), leathery fruit peel/skin with whitish-powdery gloss, and depressions or ridges/ grooves developed at the stylar scar end of the fruit, could be applied/ used as recommended visual attributes/characteristics of mango fruit harvest maturity indices appropriate for export and local markets.

Ranges of appropriate harvest time for fruits of Haden, Kent, Palmer, and Keitt mango varieties at physiological maturity were determined and established to be 109-115, 123-129, 130-136, and 137-143 days from fruit-set, respectively, for early harvest; 116-122, 130-136, 137-143, and 144-150 days from fruit-set, respectively, for mid-harvest; and123-129, 137-143, 144-150, and 151-157 days from fruit-set, respectively, for late harvest.

\section{Acknowledgments}

Mr. Edward Twum (Director of Prudent Export and Import Company), Accra, Ghana, is gratefully acknowledged for his cooperation, financial, moral, and academic support.

\section{Conflicts of interest}

Authors declare no conflict of interest exists.

\section{References}

1. GEPA. Mango - Ghana export promotion authority Buyer Portal. GEPA sector profile of mangoes from Ghana - sector capabilities, reasons to buy, trade performance, featured exporters, and useful links. 2018. Retrieved from www.gepaghana.org.

2. GFPED. Ghana Fresh Produce Exporters'Directory. 2007:20.

3. McGovern TW, LaWarre S. Botanical briefs: the mango tree-Mangifera indica L. Cutis. 2001;67(5):365-366.

4. Okorley EL, Acheampong L, Abenor MT. The current status of mango farming business in Ghana: A case study of mango farming in the Dangme West District. Ghana Journal of Agricultural Science. 2014;47(1):1-2.

5. Litz, RE. The mango: botany, production and Uses. Tropical research and education centre. University of Florida, USA. CABI Publishing, CAB International, Wallingford, Oxon OX10 8DE, UK. 2003;587.

6. Slaughter DC. Nondestructive maturity assessment methods for mango: a review of literature and identification of future research needs. department of biological and agricultural engineering, University of California, Davis. 2009.
7. Micah JA, Inkoom EW. Overcoming constraints in mango production in Ghana. International Journal of Agricultural Science and Research (IJASR). 2016;6(5):147-154.

8. Kitinoja L, Kader AA. Small-scale postharvest handling practices: a manual for horticultural crops. 5th ed. UC Davis. 2015.

9. Iqbal M. Post-harvest handling of mangoes. 2015.

10. IPGRI. Descriptors for mango. international plant genetic resources institute. Rome. 1989.

11. Singh B, Singh H, Chakraborty I, et al. Physicochemical properties of three commercial varieties of mango (Mangifera indica L.) in West Bengal. Conference paper: national seminar on integrated approaches in horticulture for sustainable development, At PalliSiksha Bhavana (Institute of Agriculture), Visva-Bharati, Sriniketan, West Bengal, India. 2014.

12. Teutsch B. 100 Under \$100: Tools for reducing postharvest losses. Kitinoja, editor. Publisher: The Postharvest Education Foundation, La Pine, Oregon 97739 USA 2019 C. 2018:310.

13. Marques EJN, De Freitas ST, Pimentel MF, et al. Rapid and nondestructive determination of quality parameters in the "Tommy Atkins" mango using a novel handheld near infrared spectrometer. Journal of Food Chemistry. 2016;197:1207-1214.

14. Joyce DC, Hockings PD, Mazucco RA, et al. Heat treatment injury of mango fruit revealed by non-destructive magnetic resonance imaging. Postharvest Biology and Technology. 1993;3:305-311.

15. Kouno Y, Mizuno T, Maeda H, et al. Feasibility studies into NIR technique for measurement of internal quality of some tropical fruits. In: Champ BR \& Highley E, et al. editors. Postharvest Handling of Tropical Fruits. $1994 ; 385-387$.

16. Ledesma N, Richard J, Campbell, et al. Training and pruning a mango orchard to improve blooming and yield in south florida. 2016.

17. Obeng P. Personal communication. Principal export development officer and head of the agriculture section of the Ghana export promotion council (GEPC). Ghana Export Promotion Council, Ghana. 2007.

18. Twum E. Personal communication. Prudent export and import company limited director, Ghana. 2008.

19. Iqbal M. All About/Orchards/Mangoes. Post-harvest handling of mangoes www. 2001-2006 Pakissan.com. 2001.

20. Abu M. Quality criteria for mango export in Ghana. Ph.D Thesis submitted to the school of graduate studies. Kwame Nkrumah University of Science and Technology, Kumasi, Ghana. Published, 2010;172.

21. Abu M, Olympio NS, Darko JO, et al. The mango industry in Ghana. Ghana Journal of Horticulture. 2010;9:135-147.

22. Dadzie BK, Orchard JE. Routine post-harvest screening of banana/ plantain hybrids: criteria and methods. INIBAP Technical Guidelines 2. International plant genetic resources institute, Rome, Itali; international network for the improvement of banana and plantain, montpelier, France; ACP-EU technical centre for agricultural and rural cooperation, Wageningen, The Netherlands. 1997;63.

23. Manasa B, Jagadeesh SL, Thammaiah N, et al. Colour measurement of ripening mango fruits as influenced by pre-harvest treatments using $\mathrm{L}^{*}, \mathrm{a}^{*}, \mathrm{~b}^{*}$ coordinates. Journal of Pharmacognosy and Phytochemistry. 2019;8:2466-2470.

24. Snedecore GW, Cochran WG. Statistical methods (seventh ed.), Iowa State Univ. Press, Ames, Iowa, USA. 1980;507.

25. MTSS. Mango trial sea shipment. Trade and investment program for a competitive export economy/united states agency for international development (TIPCEE/USAID) project. 2004.

26. MIR. Market intelligence report. FAGE, Ghana. 2008:2. 
27. Asgharzade A, Valizade GA, Babaeian M. Investigating the effect of boron spray on yield, nutrient content, texture, and brix index of apple (Sheikh Amir Variety) in Shirvan region. African Journal of Microbiology Research. 2012;6(11):2682-2685.

28. Ambuko J, Karithi E, Hutchinson M, et al. Postharvest shelf life of mango fruits stored in a CoolbotTM cold room. Acta Horticulturae. 2018;1225:193-198.

29. Baloch MK, Bibi F. Effects of harvesting and storage conditions on the Post- harvest quality and shelf life of mango (Mangifera indica L.) fruit. 2012 .

30. Ahmad MS, Siddiqui MW. Factors affecting postharvest quality of fresh fruits. springer international publishing, Basel. 2015.

31. Okoth EM, Sila DN, Onyango CA, et al. Evaluation of chemical and nutritional quality attributes of selected mangovarieties at three stages of ripeness, grown in lower eastern province of Kenya - Part 2. J Anim. Plant Sci. 2013;17(3):2619-2629.

32. Hemat E, Elsheshetawy A, Mossa WK, et al. Comparative study on the quality characteristics of some Egyptian mango cultivars used for food processing. Annals of Agricultural Sciences. 2016;61(1):49-56.

33. Spinelli L, Rizzolo A, Vanoli M, et al. Nondestructive assessment of fruits biological age in Brazilian mangoes by time-resolved reflectance spectroscopy in the 540-900 nm spectral range. In: Inside Food Symposium. April, Leuven, Belgium. 2013;9-12.

34. Vásquez-Caicedo AL, Neidhart S, Pathomrungsiyounggul $\mathrm{P}$, et al Physical, chemical and sensory properties of 9 Thai mango culitvars and evaluation of theirtechnological and nutritional potential. In: international symposium 'sustaining food security and managing natural resources in southeast asia: challenges for the 21th Century, 08.- 11.01.2002, Chiang Mai, Thailand. 2002.
35. Singh, NI, Dhuique-Mayer C, Lozano Y. Physico-chemical changes during enzymatic liquefaction of mango pulp (cv. Keitt). J Food Processing and Preservation. 1999;24(1):73-85.

36. Muengkaew R, Chaiprasart P, Warrington I. Changing of physiochemical properties and color development of mango fruit sprayed methyl jasmonate. Sci Hortic. 2016;198:70-77.

37. Desphande AB., Chidley HG, Oak PS, et al. Data on changes in the fatty acid composition during fruit development and ripening of three mango cultivars (Alphonso, Pairi, and Kent) varying in lactone content. Data in Brief. 2016;9:480-491.

38. Deshpande AB, Anamika $\mathrm{K}$, Jha V, et al. Transcriptional transitions in Alphonso mango (Mangifera indica L.) during fruit development and ripening explain its distinct aroma and shelf life characteristics. Sci Rep. 2017;7(1):1-19.

39. Wongmetha $\mathrm{O}, \mathrm{Ke} \mathrm{L}$, Liang Y. The changes in physical, biochemical, physiological characteristics and enzyme activities of mango cv. Jinhwang during fruit growth and development. J Life Sci. 2015;(72-73):1-6.

40. Gill PPS, Jawandha SK, Kaur N, et al. Physicochemical changes during progressive ripening of mango (Mangifera indica L.) cv. Dashehari under different temperature regimes. J Food Sci Tech. 2017;54(7):1-7.

41. Ellong EN, Adenet S, Rochefort K. Physicochemical, nutritional, organoleptic characteristics, and food applications of four mango (Mangifera indica L.) varieties. Food Nutr Sci. 2015;6:242-253.

42. Hofman PJ, Ledger SN. Using a supply chain approach to guide R\&D. Acta horticulture. 2006;699:219-226.

43. Swami SB, Thakor NJ, Wagh SS. Effect of temperature on viscosity of kokum, karonda, mango pulp, and cashew apple syrup. Agric Eng Int CIGR J. 2013;15(4):281-287. 